\title{
Ben Jonson no Brasil: os paratextos das traduções brasileiras de Volpone, ou A Raposa $(1605 / 1606)$
}

\author{
Amanda Fiorani Barreto* e Leonardo Bérenger Alves Carneiro**
}

O presente artigo aborda aspectos da inserção do dramaturgo inglês Ben Jonson (1572-1637) no Brasil a partir da análise dos paratextos de duas traduções publicadas de uma peça de sua autoria, a única em todo o vasto cânone jonsoniano a ser traduzida e publicada para o português brasileiro: Volpone, ou A Raposa (1605/1606). A primeira dessas traduções é assinada Newton Belleza e publicada em 1977 pela editora Emebê; a segunda, por Ganymédes José, em 1987 pela Ediouro. Pretende-se, ainda, levantar possíveis hipóteses para a escassa presença do dramaturgo em nosso idioma, levando em conta o gênero (cômico) no qual Jonson produziu a imensa maioria de suas peças, o estilo caracteristicamente classicista de seu teatro, bem como a posição do autor em relação a outros dramaturgos contemporâneos a ele, com atenção particular à centralidade de William Shakespeare (1564-1616) em todo e qualquer discurso sobre o drama elisabetano-jacobino no Brasil.

Nossa análise dos paratextos das duas traduções está diretamente endividada com as definições de Gérard Genette (1930-2018) estabelecidas em seus livros Paratextos Editoriais (2009) e Palimpsestos: a literatura de segunda mão

\footnotetext{
* Programa de Pós-Graduação em Estudos da Linguagem, Pontifícia Universidade Católica do Rio de Janeiro (PUC-Rio)

** Pontifícia Universidade Católica do Rio de Janeiro (PUC-Rio)
} 
(2010). Paratextos, de acordo com a hoje clássica definição de Genette, podem ser compreendidos como componentes constitutivos do livro, e que inserem a obra em uma cultura receptora, afetando a sua circulação. Nas palavras do próprio teórico, paratextos são "aquilo por meio de que um texto se torna livro e se propõe como tal a seus leitores, e de maneira mais geral ao público." (GENETTE, 2009, p. 9). Genette situa, então, os paratextos em uma posição intermediária, como em uma “'zona indecisa' entre o dentro e o fora, sem limite rigoroso, nem para o interior (o texto) nem para o exterior (o discurso do mundo sobre o texto)" (GENETTE, 2009, p. 9). Além disso, afirma até mesmo "que não existe, e que jamais existiu, um texto sem paratexto." (GENETTE, 2009, p. 9).

É em Paratextos Editoriais que Genette chama atenção para o lugar do paratexto, definindo algumas diferenciações baseadas nessa localização. $O$ peritexto, a categoria de paratextos que o crítico diz ser a mais comum, se caracteriza como algo que se localiza "em torno do texto, no espaço do mesmo volume, como o título ou o prefácio e, às vezes, inserido nos interstícios do texto, como os títulos de capítulos ou certas notas" (GENETTE, 2009, p. 12). Já a segunda categoria, o epitexto, se situaria "ainda em torno do texto, mas a uma distância mais respeitosa (ou mais prudente), todas as mensagens que se situam, pelo menos na origem, na parte externa do livro" (GENETTE, 2009, p. 12, grifo nosso). O paratexto, neste momento da formulação de Genette, funciona como um conceito guarda-chuva que abarca tanto o peritexto quanto o epitexto. De forma mais simplificada, "paratexto = peritexto + epitexto" (GENETTE, 2009, p. 12). Ou, ainda, conforme sintetizado por Batchelor (2018), que nos lembra das nuances por detrás das categorias de Genette, “peritexto é paratexto (mas paratexto não é apenas peritexto)"1 (p. 11).

Já em seu livro Palimpsestos: a literatura de segunda mão (2010), Genette aborda os paratextos por outro viés, ao falar de cinco tipos de relações transtextuais, sendo duas delas a paratextualidade e a metatextualidade, que se configuram como categorias importantes para o presente trabalho. Nesse novo

\footnotetext{
${ }^{1}$ A tradução desta citação, assim como as demais nas quais não houver indicação de tradutor/a, são de nossa autoria. No original: "Peritext is paratext (but paratext is not just peritext)".
} 
paradigma do autor, os paratextos - que são para Genette "uma mina de perguntas sem respostas" (GENETTE, 2010, p. 16) - consistiriam nas seguintes partes do texto:

[T]ítulo, subtítulo, intertítulos, prefácios, posfácios, advertências, prólogos, etc.; notas marginais, de rodapé, de fim de texto; epígrafes; ilustrações; release, orelha, capa, e tantos outros tipos de sinais acessórios, autógrafos ou alógrafos, que fornecem ao texto um aparato (variável) e por vezes um comentário, oficial ou oficioso, do qual o leitor, o mais purista e o menos vocacionado à erudição externa, nem sempre pode dispor tão facilmente como desejaria e pretende. (GENETTE, 2010, p. 15)

Diferentemente, os metatextos estabeleceriam uma relação crítica, podendo ser também "chamad[os] mais corretamente de 'comentário[s]" (GENETTE, 2010, p. 15). Quando cruzamos essas duas noções com aquelas apresentadas por Genette em sua obra anterior, temos algumas possíveis equivalências, em que os epitextos corresponderiam ao que o autor chamou aqui de metatextos; e os peritextos ao que aqui se caracterizou como paratextos. Essa nomenclatura oferecida em Palimpsestos parece ser mais clara e intuitiva, utilizando o termo paratexto como parte agente na classificação, e não apenas como um conceito guarda-chuva. Sendo assim, optamos, em nossa análise, por aquelas conceituações mais tardias, fazendo algumas considerações quando as classificações anteriores parecerem oferecer maior clareza em relação à categorização dos textos.

No âmbito dos Estudos da Tradução, permanece certo debate acerca de como Genette considera as traduções em comparação a outros gêneros textuais em seu trabalho. O crítico as discute brevemente em sua teoria, ao dizer que "traduções devem, de uma forma ou de outra, servir como comentários do texto original"2 (GENETTE, 1997, p. 405). O autor parece estar indicando aqui uma visão de traduções como paratextos do texto original e, portanto, ocupando uma posição subserviente ao texto primário. Essa visão acerca da tradução como algo secundário em relação ao texto original é muito criticada por autores que se

2 "translations must, one way or another, serve as commentary on the original text" 
apropriam da teoria de Genette dentro do campo dos Estudos da Tradução (p.ex. Şehnaz Tahir-Gürçağlar [2013]), pois a atividade tradutória é dessa forma sempre vista em comparação a uma outra, e não em sua singularidade.

Para além do grupo de críticos mencionados acima, há ainda outros autores (p. ex., Batchelor [2018]) que admitem o quão problemática a visão genettiana se coloca para os Estudos da Tradução, mas oferecem um posicionamento um pouco mais favorável à conceituação de Genette, chamando atenção para outros aspectos de seus escritos teóricos. Como exemplo de aspecto favoravelmente recebido por parte dos estudiosos da área, temos o fato de que Genette comenta que "o paratexto - mais flexível, mais versátil, sempre transitório porque é transitivo - é, por assim dizer, um instrumento de adaptação"3 (GENETTE, 1997, p. 408). Tal perspectiva, isto é, a de que a tradução ao ocupar a posição de paratexto, torna-se também um instrumento de adaptação e abre a possibilidade de que ela, tradução, venha a influenciar a recepção do texto original, tornando-se assim um objeto de estudo em si mesmo.

Ainda discutindo traduções, Genette, em uma nota de rodapé, se refere ao caráter oficial de um paratexto ao advertir que é "um comentário para ser usado com cuidado, pois o direito de ser infiel é um privilégio autoral"4 (GENETTE, 1997, p. 405). Genette, no entanto, ao usar exemplos de textos traduzidos (p.ex. a tradução francesa de For Whom the Bell Tolls, de John Donne) parece indicar (embora nunca diga isso diretamente) que o texto traduzido pode ser considerado como um texto por si só, com seus próprios paratextos (BATCHELOR, 2018). Dessa forma, abordamos traduções neste trabalho como textos originais, considerando seus paratextos tal qual faríamos com um paratexto de uma nova edição de um trabalho original.

Além disso, precisamente como este artigo se propõe a fazer ao refletir sobre como as obras de Ben Jonson chegaram no Brasil e por quais razões elas foram pouco traduzidas no país, Batchelor afirma que

\footnotetext{
3 "The paratext - more flexible, more versatile, always transitory because transitive - is, as it were, an instrument of adaptation."

4 "commentary to be used with care, for the right to be unfaithful is an authorial privilege."
} 
paratextos têm também oferecido pistas extremamente úteis para historiógrafos literários, permitindo que eles reconstruam as histórias de publicação de autores em específico ou formulem panoramas mais claros do fluxo de obras literárias através das fronteiras"5 (BATCHELOR, 2018, p. 32).

É seguindo Batchelor que este trabalho pretende discutir a presença/ausência da obra de Jonson no Brasil ao longo da história editorial brasileira ao analisar os paratextos de suas únicas traduções publicadas.

Uma última consideração acerca de nosso ferramentário teórico se dá em relação aos conceitos de domesticação e estrangeirização estabelecidos por Lawrence Venuti (1995) como duas estratégias de tradução. A primeira consistiria em "uma redução etnocêntrica de um texto estrangeiro para valores culturais da língua de chegada"6 (VENUTI, 1995, p. 20), ou seja, uma adequação da tradução à cultura de chegada. Já a segunda se definiria como "uma pressão etnodesviante sobre esses valores para registrar a diferença linguística e cultural do texto estrangeiro"7 (VENUTI, 1995, p. 20), em outras palavras, manter o texto mais perto da cultura de partida, mesmo que isso possa causar estranhamento para o leitor. Esses conceitos nos são importantes ao tentarmos mapear as estratégias dos processos tradutórios de Newton Belleza e Ganymédes José.

\section{Ben Jonson, o teatro elisabetano/jacobino e Volpone; or, The Fox (1605/1606)}

Ben Jonson foi um dos dramaturgos mais celebrados das eras elisabetana e jacobina, e em 1597, ele já aparece nos diários de Philip Henslowe, empresário do ramo do teatro da época. Jonson também foi ator, e especula-se, inclusive, que tenha interpretado Hierônimo, o personagem principal de uma das peças mais famosas e populares de toda a era elisabetana, A Tragédia Espanhola (1592)

\footnotetext{
5 "Paratexts have also been shown to offer extremely useful clues for literary historiographers, allowing them to reconstruct the publishing histories of particular authors or formulate clearer pictures of the flow of literary works across borders."

6 "an ethnocentric reduction of the foreign text to target-language cultural values"

7 "an ethnodeviant pressure on those values to register the linguistic and cultural difference of the foreign text"
} 
de Thomas Kyd (1558-1594). Ben Jonson foi uma figura muito importante e celebrada em sua época, escrevendo peças tanto para a corte quanto para os teatros públicos e privados, além de também produzir entretenimentos para a aristocracia, com as mascaradas. O autor escreveu muitas obras, totalizando quase cinquenta peças teatrais, sendo apenas duas delas tragédias (Sejanus [1603] e Cataline [1611]), embora pareça haver indícios de que ele tenha composto outras tragédias no começo de sua carreira que não chegaram aos dias de hoje (LEECH, 2020).

Jonson ficou conhecido por sua alta estima às obras clássicas, obedecendo às unidades aristotélicas de tempo, ação e espaço, e se inspirando no estilo e conteúdo de obras greco-latinas. Curiosamente, Jonson, como Shakespeare, não frequentou as universidades prestigiadas de Oxford ou Cambridge, como outros dramaturgos da época (chamados de university wits), mas chegou a receber graus honorários de ambas as universidades mais tardiamente em sua vida por sua maestria poética. A sua formação escolar, no entanto, informou muito de sua produção. O dramaturgo estudou em uma das melhores grammar schools da época, a Westminster School, sob a tutela do grande humanista e historiador, William Camdem (1551-1623).

As obras completas de Jonson não se restringem ao campo do teatro, tendo o autor também produzido poesia lírica, epigramas, traduções e, em se tornando figura importante na corte, mascaradas tanto para o rei Jaime I quanto para o rei Carlos I. Durante ambos os reinados, colaborou diversas vezes com o arquiteto Inigo Jones (1573-1652) na encenação de mascaradas, que garantiram posição assídua do dramaturgo na corte, culminando em sua nomeação como poeta laureado pelo rei Jaime I, em 1619.

A peça Volpone; or, The Fox foi composta entre os anos de 1605/1606, durante o reinado de Jaime $\mathrm{I}$, portanto. $\mathrm{O}$ ano de 1606 foi muito importante para a carreira de Ben Jonson, com a produção de Volpone - uma de suas peças de maior sucesso - e também a mascarada Hymenaei para a corte. Volpone foi vendida para a companhia de teatro King's Men, da qual Shakespeare fazia parte e era acionista, e provavelmente teve a sua primeira performance no teatro 
público The Globe, em 1606. Especula-se, inclusive, que Richard Burbage também integrante e acionista da King's Men, além de ser um dos maiores atores de sua época - foi quem ficou encarregado de interpretar o personagem principal da peça de Jonson, Volpone.

Volpone; or The Fox 8 é uma comédia majoritariamente em versos, mas que também conta com passagens em prosa como, por exemplo, quando Volpone está disfarçado como um mountebank, traduzido por Newton Belleza como um "doutor saltimbanco", no ato 2, cena 2 da peça. A mudança de registro (do verso à prosa) nessa peça de Jonson é, então, bem marcada e está claramente relacionada às demandas do próprio enredo. A obra tem também fortes influências e ambições clássicas, como a própria dedicatória às universidades de Oxford e Cambridge indica. É ideia já estabelecida na crítica que Ben Jonson sofreu diversas influências na composição de Volpone, como da commedia dell'arte italiana, fábulas da época e outras, como iremos adentrar a seguir. O enredo de Volpone, de forma simplificada, fica por conta dos diversos planos do personagem-título - um homem veneziano muito rico e sem herdeiros - com seu criado, Mosca, para conseguir ainda mais dinheiro ao enganar três homens - Voltore, Corbaccio e Corvino - que, por sua vez, estão atrás da fortuna de Volpone.

Como indicado pela etimologia latina dos nomes dos personagens, uma das inspirações de Jonson em Volpone parece ter sido a tática de raposas em se fingirem de mortas para atraírem aves de rapina. Enredos semelhantes com o da comédia de Jonson aparecem, por exemplo, em uma parte de Historia Animalium (1557), de Conrad Gesner, um dos livros presentes na biblioteca do dramaturgo inglês (HERFORD; SIMPSON apud SCHEVE, 1950, p. 242). Outro

\footnotetext{
${ }^{8}$ Um fato a se notar sobre a peça é que é provável que a sua temporada tenha sido interrompida por um surto de peste em 1606, o que é especialmente interessante quando se considera a situação inesperada em que o mundo se encontra em 2020/2021. De fato, os primeiros sete anos do reinado de Jaime I tiveram casos de peste, alguns anos mais que outros, como foi o caso de 1606. Naquela época, quando o número de casos semanais ultrapassava trinta, os teatros eram obrigados a fechar - um dos primeiros estabelecimentos a fechar por conta da aglomeração de pessoas dentro de um espaço relativamente pequeno (SHAPIRO, 2016).
} 
livro que parece ter inspirado partes do enredo da comédia é The History of Reynard The Fox (1481), uma tradução por William Caxton de Roman de Renart "que identifica a vítima da raposa como a esposa do corvo (isto é, Celia na peça)"' (PARKER, 1999, p. 14).

Ainda pensando sobre as influências que se fazem presentes em Volpone, é necessário que retornemos aqui à presença de aspectos textuais oriundos da commedia dell'arte italiana na comédia de Jonson. Essa forma de teatro atingiu o seu apogeu popular na segunda metade do século XVI, e Jonson estava ciente desse gênero, como fica evidente quando "em II.iii Corvino compara a si mesmo ao 'Pantalone di Bisognosi', o marido ciumento e velho da commedia, Celia a 'Francisciana', uma jovem atrevida e amoral, e Volpone-Scoto a 'Flamineo', um dos jovens amantes da commedia"10 (PARKER, 1999, p. 21). A comparação de Corvino, no entanto, parece ser sarcástica, pois, embora ele seja um marido ciumento, é Volpone quem se encaixa melhor nessa posição de Pantalone ${ }^{11}$, sendo ele um homem rico e ganancioso. Como apontado por Brian Parker (1999),

\begin{abstract}
Pantalone era um homem velho, magro, amante do dinheiro e curioso. [...] Entre os seus truques favoritos estava a espionagem, como Volpone em V.iii; ele é frequentemente apresentado cantando ao som de alaúde, embora sua voz, como a de uma raposa, seja descrita como dura e desagradável ${ }^{12}$ (PARKER, 1999 , p. 22-23).
\end{abstract}

É importante levar em consideração essa e outras influências sofridas pelo dramaturgo na composição de Volpone, em um entendimento de que é característica constitutiva de todo o teatro elisabetano-jacobino seu aspecto acentuadamente polifônico e dialógico, que deve ser sopesado pelo estudioso

\footnotetext{
9 "which identifies the fox's victim as the crow's wife (i.e. Celia in the play)."

10 "in II.iii Corvino compares himself to 'Pantalone di Bisognosi', the jealous old husband of the commedia, Celia to 'Francisciana', its saucy, amoral wench, and Volpone-Scoto to 'Flamineo', one of the commedia's young lovers."

${ }^{11}$ A Figura 1 do Anexo I oferece uma ilustração para esse tipo da commedia dell'arte.

12 "Pantolone was a lean, money-loving, and inquisitive old man. [...] Among his favourite tricks was eavesdropping, like Volpone in V.iii; he is often depicted as singing to a lute, though his voice, like the fox's is described as harsh and unpleasant."
} 
dessas obras, na medida em que tal característica traz possibilidades interpretativas ainda mais plurais às peças de todo o período.

\section{As traduções brasileiras de Volpone, ou a Raposa}

Como apontado acima, Ben Jonson foi um autor muito celebrado em seu tempo e é estudado até hoje ao redor do mundo. A sua obra, no entanto, foi muito pouco traduzida para o português brasileiro ao longo dos séculos. De fato, somente têm-se duas traduções publicadas ${ }^{13}$ de peças do dramaturgo, ambas de sua comédia Volpone; or, The Fox. Curiosamente, a dramaturgia de Ben Jonson é pouco traduzida em outros países lusófonos; em Portugal, por exemplo, a obra do dramaturgo também não é muito difundida, sendo O Alquimista (1610) e Volpone as suas únicas peças com traduções publicadas naquele país (ZURBACH, 2007). Se nos focarmos especificamente nos paratextos (textos a serem analisados neste trabalho), é interessante destacar que apenas Newton Belleza traduz o paratexto original de Ben Jonson à peça Volpone, ao contrário de Ganymédes José, que ignora essa parte do texto do dramaturgo e divide o seu projeto em capítulos, como um romance.

\section{A tradução de Newton Belleza}

A primeira obra que aqui analisamos é a edição de Volpone, ou A Raposa traduzida por Newton Belleza, que foi publicada pela editora Emebê em 1977. O volume faz parte de uma coleção intitulada Coleção Teatro Clássico, na qual também estão presentes outras três traduções de Belleza: As Bacanas (1977) de Plauto, Amansando Catarina (1977) de William Shakespeare e Peleás e Melisandra (1977) de Maurice Maeterlinck. Newton Belleza foi autor de romances, contos, peças de teatro e traduções. Não se tem muitas informações sobre o autor hoje

\footnotetext{
${ }^{13}$ É importante chamar atenção para a palavra "publicadas", porque temos casos aqui no Brasil de traduções de peças de Jonson que não chegaram a ser lançadas editorialmente como, por exemplo, a tradução de Jorge Furtado para o seu documentário inspirado na peça homônima O Mercado de Notícias (2014); e outra tradução de Volpone, ou A Raposa produzida por Neyde Venziano em colaboração com Ronaldo Diaféria para uma produção teatral (2016).
} 
em dia, mas pode-se ter uma ideia da amplitude de sua atuação pela lista de publicações assinadas por ele, contida ao fim da edição de Volpone, ou A Raposa.

É interessante notar o destaque conferido ou não ao nome do tradutor na edição de Volpone. Nessa tradução da peça de Jonson, o nome de Newton Belleza aparece logo na capa, com uma fonte igual (senão maior) àquela usada para o nome de Ben Jonson ${ }^{14}$. Isso denota o destaque dado para o tradutor, que pode ser atribuído a diversos fatores como, por exemplo, as próprias condições em que a tradução foi contratada ou adquirida pelos editores, ou a notoriedade do tradutor naquele momento, entre outras possibilidades. Esse aspecto da edição será especialmente relevante quando compararmos o tratamento dado a Ganymédes José.

O primeiro paratexto da edição não conta com a indicação de quem o escreveu, mas, pelo seu conteúdo, pode-se inferir que tenha sido alguém da própria editora. $\mathrm{O}$ texto elabora um pouco sobre o título da coleção, além da contribuição almejada com a tradução das obras, e um reconhecimento da dificuldade de tradução dessas peças. Uma das primeiras informações do paratexto fala sobre a vontade inicial de Belleza de publicar as traduções dessa coleção em um único volume, que ele tinha a intenção de intitular Teatro de Newton Belleza - Traduções de Quatro Obras Clássicas. O texto indica que a publicação dos títulos em volumes separados "foi uma alternativa que lhe foi proposta e aceita pelo autor [Newton Belleza]" (A COLEÇÃO, 1977, p. 9).

A data de produção dessas traduções de Belleza e a relação do tradutor com a editora são também dignas de nota, pois a tradução de Volpone parece ter sido produzida na década de $1950^{15}$, sendo somente publicada pela editora Emebê no final da década de 1970. Isso pode ser indício, em meio a outras possibilidades, de que elas não foram encomendadas pela editora, mas sim compradas de Newton Belleza quando já prontas para serem publicadas, ao

\footnotetext{
14 Ver Figura 3 do Anexo I para foto da capa da edição de 1977.

${ }^{15}$ Informação que pode ser inferida pela data da resenha de autoria de Eugênio Gomes produzida sobre a tradução.
} 
contrário da situação de Ganymédes José com a editora Tecnoprint (Ediouro), como discutiremos mais à frente.

O paratexto em seguida descreve a obra de Jonson como uma peça “[...] do teatro elizabetiano pelo seu segundo autor mais representativo (com uma posição estética antagônica à do seu mais alto representante)" (A COLEÇÃO, 1977, p. 9). Aqui, o texto chamou atenção para um aspecto importante quando se discute a obra de Jonson, o seu estilo, que é marcadamente diferente da forma com que Shakespeare escreve, por exemplo. O paratexto inicial também parece adotar um tom escusatório em relação às versões publicadas, e, ao mesmo tempo, reconhece a dificuldade do processo tradutório, como o seguinte trecho ilustra:

\footnotetext{
Se de um lado é difícil (ou quase impossível) a tradução, como todos sabem, de outro é ainda muito mais difícil a gente recolocar-se no ambiente e dispor dos instrumentos de trabalho de uma época, ainda que no uso direto da suposta mesma língua. É forçoso, portanto, que nos contentemos com as versões possíveis de uma época para outra, dentro de uma condição que resulta das irreversíveis transformações do mundo em que vivemos. (A COLEÇÃO, 1977, p. 9, grifo nosso)
}

O paratexto, então, adota um tom que podemos compreender como conformado com o fato de que os leitores têm que se contentar com o que lhes é oferecido, sendo a tradução um ofício "quase impossível". Dessa forma, o texto parece considerar a tradução em subordinação ao texto original. Além disso, parece desconfiar de que utilizar a "suposta mesma língua" garanta alguma facilidade nesse processo. Isso irá se relacionar diretamente com as escolhas feitas por Newton Belleza em suas traduções, pois o tradutor critica outros tradutores que se mantêm muito presos à linguagem usada no original, na medida em que acredita que cada geração tem que contribuir para o rejuvenescimento de obras mais antigas. Isso aparece até mesmo em decisões linguísticas em suas traduções, como evidenciado pela crítica a tradutores que decidem manter pronomes de tratamento mais antiquados como "vós", ainda que essa seja a tradução direta do que está no original, por exemplo. Por último, 
o trecho destacado do paratexto faz uso da palavra "versões" para se referir a traduções, ressaltando a impossibilidade de traduções fidedignas e remetendo a um ideal de fidelidade inatingível, que ecoa toda uma visão que Belleza tem de tradução, como ficará explícito na seção a seguir.

\section{Paratexto escrito por Newton Belleza}

O paratexto de Newton Belleza conta com as seguintes seções: o clima literário, a casa de espetáculo, o homem, a obra, a tradução e sugestões para montagem. É um texto relativamente extenso - principalmente em comparação ao paratexto de Ganymédes José - e traz reflexões interessantes sobre as opiniões de Belleza acerca de fidelidade, forma e outros aspectos considerados relevantes durante o processo tradutório. Como a coleção da qual Volpone faz parte conta com outras três traduções de Belleza, iremos utilizar alguns trechos e informações dessas outras traduções para complementar a visão que ele oferece nesta edição. Ao máximo que se sabe por meio de trechos de seus prefácios, três das quatro ${ }^{16}$ peças da coleção Teatro Clássico foram traduzidas por Belleza para prosa, o que faz com que o cruzamento dos prefácios dessas obras seja especialmente interessante de se analisar para termos um panorama mais abrangente das visões de Belleza sobre tradução. A tempo deste trabalho, tivemos acesso apenas a trechos do paratexto de Amansando Catarina e alusões ao paratexto de As Bacanas, além, evidentemente, da edição da peça de Jonson aqui trabalhada.

As primeiras seções do paratexto fornecem um panorama para os leitores das eras elisabetana e jacobina, além do teatro, da época e da biografia de Ben Jonson. Belleza afirma que William Shakespeare foi um sucessor de Christopher Marlowe, mas descreve Jonson como um autor que é "praticamente um sucessor de ninguém, no seu tempo" (BELLEZA, 1977b, p. 18), graças ao seu estilo diferenciado em relação aos outros dramaturgos de sua época, com a sua

16 Volpone, ou A Raposa de Ben Jonson; Amansando Catarina de William Shakespeare; e As Bacanas de Plauto. Não se pôde averiguar se o mesmo acontece com Peléas e Melisandra de Maurice Maeterlinck a tempo para este trabalho. 
elevada estima pelos clássicos, obedecendo às unidades aristotélicas e inspirando-se em obras greco-latinas, além de seu estilo cômico. Além disso, diz que "[a] comédia de Ben Jonson [ocupa] uma posição singular na história da comédia" pela "peculiaridade do cômico profundo e poliédrico" de suas peças (BELLEZA, 1977b, p. 24).

Belleza destaca que nem mesmo William Shakespeare escapou da influência de Jonson, que, de acordo com o tradutor, aplicou a teoria de "humor" de Ben Jonson em personagens de Henrique IV (1600) e As Alegres Comadres de Windsor (1602), como Falstaff e Dame Quickly, como exemplos. Além disso, ressalta a importância de Ben Jonson para a posteridade, ao dizer que

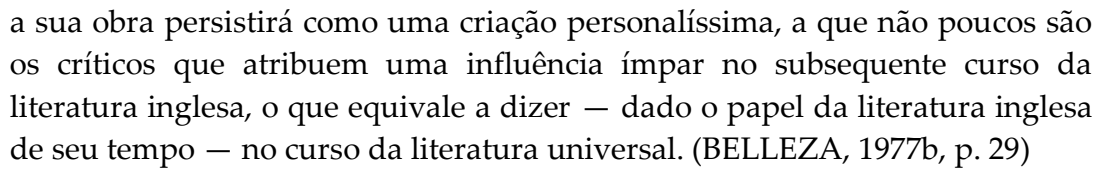

A seção sobre a tradução em si discute um pouco sobre o projeto tradutório nesta peça de Jonson, comentando também algumas de suas opções nesse processo. A primeira grande escolha de Belleza a se destacar é aquela por traduzir Volpone para a prosa. É importante ressaltar, como já mencionado, que a peça de Jonson no original é, em sua maioria, em verso, tendo mudanças para prosa bem marcadas. Como comentado acima, a tradução para a prosa foi a opção que Belleza reiterou em outras peças dessa coleção, começando, inclusive, a seção sobre a tradução explicando tal escolha. O tradutor faz referência a outra tradução da coleção, ao dizer que reconhece "que a apreciação de uma obra em sua plenitude fica prejudicada quando se traduz em prosa o que foi escrito em verso" (BELLEZA, 1977b, p. 30). Essa, no entanto, foi a escolha do tradutor nesta e em outras peças, e a justificativa para isso parece vir logo depois quando Belleza afirma que: “[...] salientamos também que há menos risco de erro de interpretação em prosa do que em verso, porquanto a exigência da métrica pode sacrificar a clareza e o sentido da obra, com acréscimo de novos perigos da traição permanente a que está sujeito o tradutor" (BELLEZA, 1977b, p. 30). 
Percebe-se então uma preocupação no final da fala de Newton Belleza com aquela máxima ouvida por tradutores, Traduttore, traditore (Tradutor, traidor), algo que parece tê-lo levado ao que parecia ser para ele o caminho com menos riscos - traduzir a peça para prosa. Belleza continua abordando a questão em seu paratexto de Amansando Catarina, de William Shakespeare, ao relatar que

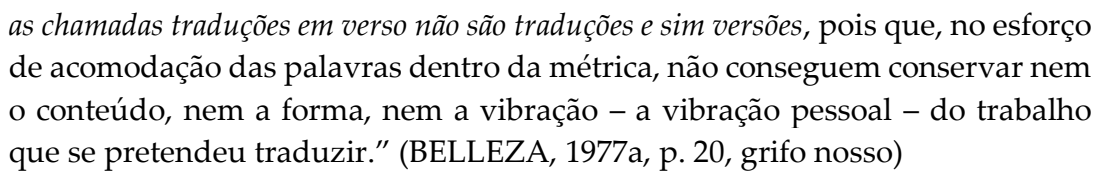

Aqui temos um posicionamento interessante, pois o autor desvela por meio desse trecho um pouco da sua noção de fidelidade. Belleza parece acreditar ser impossível manter a forma e o conteúdo e, portanto, decide sacrificar a forma em prol de um ideal de fidelidade ao conteúdo. Além disso, temos algo ainda mais complexo de se definir (e traduzir) nesse trecho de Belleza, quando ele fala que um texto tem, então, uma "vibração pessoal", e que esse aspecto também seria perdido ao tentar acomodar o texto dentro da métrica.

Ainda sobre a questão da forma, Belleza se justifica utilizando T.S. Eliot como exemplo ao dizer que o autor estadunidense "confunde lamentavelmente poesia com verso" (BELLEZA, 1977b, p. 31) em seu livro Poetry and Drama (1951), afirmando ainda que Eliot "milita a favor da prosa [...] [pelo] fato de ser ela mais facilmente adaptável às exigências do palco e à aceitação do público de hoje" (BELLEZA, 1977b, p. 31). Dessa forma, Belleza reconhece essa posição do crítico norte-americano como dizendo que "o uso da prosa [serviria como] uma modalidade de atualização da obra que foi em outros tempos escrita em verso" (BELLEZA, 1977b, p. 31).

Em uma resenha da tradução de Belleza, o crítico brasileiro Eugênio Gomes responde justamente a esses comentários do tradutor sobre Eliot ao dizer que é "impossível concordar com o esclarecido tradutor, quanto à afirmativa de que, no seu estudo Poetry and Drama, T.S. Eliot 'confunde lamentavelmente poesia com verso'” (GOMES, 1977, p. 14). Belleza, então, buscou em outros 
autores razões para justificar a sua escolha de traduzir essas peças clássicas para a prosa, mas, se utilizarmos apenas a resposta de Gomes, percebemos como nesse caso o tradutor parece ter lido "errado" a obra de T.S. Eliot.

Como evidenciado pela presença de uma seção com sugestões para montagem, Belleza parece ter traduzido a peça de Jonson com o intuito dela ser encenada, ao contrário do projeto encabeçado por Ganymédes José. O tradutor, inclusive, menciona que fez "uma atualização neutra para a língua", pois, do contrário, seria "inaceitável, senão difícil, tentar a representação da peça hoje (e foi ela traduzida com a esperança de ser representada) com o tratamento de 'vós' entre duas pessoas que se falam" (BELLEZA, 1977b, p. 32). Esse aspecto de sua tradução pode também ter influenciado a decisão de Belleza por traduzir a peça para prosa.

Tais comentários de Belleza nos levam a outra escolha adotada pelo tradutor, em relação aos pronomes de tratamento. Belleza deixa claro que discorda de tradutores que mantêm o linguajar da obra original, pois acredita que "uma tradução [...] não pode deixar de ser também uma obra de rejuvenescimento" (BELLEZA, 1977b, p. 32). Em sua tradução de Volpone, decide então mudar os pronomes de tratamento para a terceira pessoa, "você", em vez de utilizar "vós". Como ele mesmo afirma, "é, portanto, para os que falam e escrevem como falamos e escrevemos hoje que devemos escrever e falar" (BELLEZA, 1977b, p. 31).

No último parágrafo de seu paratexto acerca de sua tradução, Belleza rapidamente fala algo que pode ser bem interessante para se notar em relação a sua estratégia de tradução com Volpone, ao dizer que, "ao traduzir Volpone do original, [...] nos valemos também da tradução francesa de Georges Duval - Ernest Flammarion, Éditeurs, Paris" (BELLEZA, 1977b, p. 32, grifo nosso). O tradutor admite que a tradução francesa "apresenta sérias falhas e omissões" (BELLEZA, 1977b, p. 32), mas que "as traduções existentes noutras línguas nos prestam excelente serviço ainda que não sejam em si grande coisa" (BELLEZA, 1977b, p. 32). 
Esse uso de uma tradução francesa ao produzir a sua própria tradução para o português brasileiro pode ser atribuído a diversos motivos, como o uso feito por muitos tradutores de textos intermédios para produzir suas próprias traduções. Se essa for a razão, a situação traçaria um paralelo interessante com traduções portuguesas de Ben Jonson, em que "o uso paralelo do texto fonte e do texto intermédio em tradução é também uma característica da maior parte das traduções que compõem o repertório teatral no qual a tradução desta comédia de Ben Jonson se insere" (ZURBACH, 2007, p. 116). Além disso, uma outra possibilidade é que o uso da tradução francesa esteja inserido em uma tradição da sociedade brasileira em relação à influência francesa aqui exercida por muito tempo. Para se entender a dimensão da influência francesa no Brasil, basta pensar que na Constituinte de 1823 a língua francesa competiu com o português e o Tupi na decisão para a língua nacional (WYLER, 2003). Essa influência "foi decisiva para formar a nossa visão de mundo e, consequentemente, nossa visão de tradução como parte desse mundo" (WYLER, 2003, p. 57). Naquele momento, muitos textos franceses estavam sendo traduzidos para a prosa, então fica a dúvida se isso pode de alguma forma ter afetado a decisão de Belleza ao traduzir essas peças clássicas para a prosa.

\section{A resenha de Eugênio Gomes}

É também constante da edição de Volpone pela Editora Emebê uma resenha da tradução de Newton Belleza, assinada por Eugênio Gomes, escritor e crítico literário brasileiro. Gomes ocupou o cargo de diretor da Biblioteca Nacional e da Casa de Rui Barbosa, além de ter publicado um livro crítico sobre o ilustre contemporâneo de Jonson: Shakespeare no Brasil (1961). A resenha em questão foi publicada primeiramente no suplemento Letras e Artes do jornal A manhã, em 1954 ${ }^{17}$. A sua posição dentro da edição de Volpone é interessante, vindo antes do paratexto do próprio Belleza e da tradução em si, embora Eugênio Gomes esteja, obviamente, respondendo a esses dois textos. Sendo assim, decidimos fazer a

\footnotetext{
${ }^{17}$ Disponível como Figura 2 do Anexo I.
} 
análise da resenha depois do paratexto de Belleza, embora essa opção subverta a ordem adotada na edição. A sua data de publicação no jornal também é indicativa da data em que a tradução de Belleza foi realmente produzida, já que a resenha é da década de 1950, quando a tradução só foi ser publicada pela editora Emebê no final da década de 1970.

O texto de Gomes, situado primeiramente na posição de metatexto, ou seja, a uma distância maior do texto que comenta, aparece nessa edição de 1977 numa posição que, à primeira vista, classificaríamos como de um paratexto. Para mais bem situar esse texto de Gomes, é importante voltarmos às primeiras conceituações de Genette em Paratextos Editoriais (2009) e suas noções de peritexto e epitexto. Genette diz que o epitexto (i.e., metatexto) se localizaria "ainda em torno do texto, mas a uma distância mais respeitosa (ou mais prudente), [o que englobaria] todas as mensagens que se situam, pelo menos na origem, na parte externa do livro" (GENETTE, 2009, p. 12, grifo nosso). Sendo assim, dado que o texto de Gomes aparece primeiramente fora do âmbito do livro, a resenha então seria um epitexto (ou metatexto), estabelecendo uma relação crítica com o livro sobre o qual discute.

Ao nos voltarmos à análise crítica feita por Eugênio Gomes, vale ressaltar que o crítico afirma de início ter achado a tradução de Belleza dotada de linguagem fluente, mas que sofreria com problemas de revisão em alguns momentos (GOMES, 1977). O autor concorda com muitas das escolhas tradutórias de Belleza dizendo, por exemplo, que achou "louvável a iniciativa seguida pelo tradutor de verter em prosa Volpone" (GOMES, 1977, p. 15), embora admita que essa escolha tenha gerado sacrifícios ao texto original como decorrência. Além disso, parece estar em afinidade com o tradutor ao afirmar que "cada geração deve contribuir para o rejuvenescimento de tais peças", entendendo por "tais" aquelas "peças de época remota" (1977, p. 15).

Outro aspecto interessante comentado por Gomes é sobre os nomes dos personagens, o que nos remete à relação mencionada anteriormente entre nomes, caracterização e o comportamento dos animais aos quais eles fazem alusão. O crítico fala sobre a escolha de Belleza em não traduzir os nomes dos 
personagens Politick Would-be e Fine Madam Would-be, já que eles também trazem consigo significado em seus nomes. Newton Belleza, em seu paratexto, se mostrou bem preocupado com a recepção dessa obra pelos leitores brasileiros. A sua escolha de traduzir para prosa - que ele mesmo diz gerar "menos risco de erro de interpretação" (BELLEZA, 1977b, p. 30) do que para verso - parece indicar um esforço para domesticar (VENUTI, 1995) o texto em busca de um ideal de fidelidade que se desdobra para além de preocupações com a forma e outros aspectos do texto.

Os conceitos de domesticação e estrangeirização de Lawrence Venuti marcam o tratamento dado ao texto no processo de tradução em relação às culturas de chegada e partida, e são relevantes quando consideramos algumas das escolhas feitas por Newton Belleza. A domesticação consistiria em situações em que o tradutor se mantém mais próximo à cultura de chegada, podendo até mesmo fazer concessões para facilitar esse estreitamento. Já com a estrangeirização, o tradutor se manteria mais perto da cultura de partida, mesmo que isso possa causar estranheza na cultura de chegada. Ao não traduzir os nomes dos personagens, no entanto, Belleza parece ir na direção oposta, ao distanciar a obra de seus leitores brasileiros com essa estrangeirização (VENUTI, 1995) que, de acordo com Gomes, "a um leitor ou ouvinte brasileiro que não conheça o significado escapará totalmente o sentido irônico desses epítetos" (GOMES, 1977, p. 16).

\section{A tradução de Ganymédes José}

O segundo projeto tradutório abordado neste artigo é a edição de Volpone ou A Raposa de 1987 da Editora Tecnoprint (Ediouro), assinado por Ganymédes José (1936-1990), que foi autor de mais de 150 obras, a maioria de literatura infantojuvenil. José foi um autor muito prolífico nas décadas de 1970 e 1980, ganhando, inclusive, o Prêmio Jabuti de literatura infantil em 1985. Ganymédes José, como Belleza, também parece ocupar posição de destaque na edição, com o seu nome 
aparecendo na capa ${ }^{18}$. Em comparação a Belleza, no entanto, menor ênfase é dada a seu nome, que está em um tamanho comparativamente menor que o nome de Ben Jonson. Isso pode indicar, entre outras possibilidades, uma relutância em reconhecer o papel intrusivo de José na obra de Jonson nessa instância, que adapta a peça jacobina para outro gênero literário.

Ao contrário da edição de 1977, este projeto da peça jonsoniana se anuncia logo na capa como uma adaptação de Ganymédes José. De fato, o prefácio de José se preocupa em sua maior parte com o fato de se tratar de uma adaptação - como e por que a escolha foi feita, e o que ele pretendia com a sua versão da peça jacobina. José começa o seu paratexto comentando suas inquietações acerca de como essa peça seria lida e recebida, ao levantar as perguntas:

[...] como transmitir ao público o clima de uma peça escrita há mais de três séculos? Como dosar o vocabulário atualizando-o, sem comprometer o texto? Como levar o público a enxergar um texto teatral, onde não existem narrações, descrições, citações, explicações e demais recursos que levam o leitor a visualizar um romance, por exemplo? (JOSÉ, 1987, p. 5, grifo nosso)

Essas ansiedades parecem desmerecer o gênero ao qual a obra de Jonson pertence, sendo ela um texto teatral e, portanto, não tendo que se adequar às expectativas de um romance, que é precisamente a comparação feita pelo tradutor no paratexto. Como decorrência dessa comparação, o autor decide por fazer uma adaptação da peça para suprir esses elementos que ele parece acreditar que faltam na obra de Jonson, efetivamente mudando o gênero literário do texto, que passa a ser dividido em capítulos, como um romance, ao invés de atos e cenas, como é o costume com peças. O que segue é um parágrafo que parece ter por detrás a mesma preocupação expressa por Belleza em seu paratexto, a do tradutor como traidor. Para apaziguar essas apreensões, ele se contradiz diversas vezes no seguinte fragmento:

\footnotetext{
18 Ver Figura 4 do Anexo I.
} 
Portanto, sem adulterar (porém atualizando) os diálogos da genial obra de Ben Jonson, escrevi a minha versão cinematograficoliterária... se é que tal coisa existe! Respeitei, porém, na íntegra e sem alterações (nem omitindo e nem inserindo), quaisquer falas do texto original, transformando a peça em um livro inédito que ofereço aos estudantes. (JOSÉ, 1987, p. 5, grifo nosso)

José então segue falando sobre as suas percepções em relação ao nome dos personagens - retomando a raiz latina de Volpone - e como eles impactam o entendimento da peça. Isso desemboca na ideia do tradutor de que seria cabível então mudar o título de Volpone ou A Raposa para que todos pudessem entender essa conexão dos nomes, como ilustrado abaixo:

\footnotetext{
Cheguei à conclusão de que Volpone deve ser derivado de vulpes (raposa, em latim). Para os italianos, o nome Volpone está intimamente ligado à matreirice da raposa. Mas se em português temos Raposo, então porque não usar este nome para o malandro bem-nascido? E para evitar a redundância da palavra fox (raposa) no título original, eu havia idealizado um novo título: RAPOSÃO, O MALANDRO. (JOSÉ, 1987, p. 6, grifo nosso)
}

A editora, no entanto, não quis seguir com a ideia de José quanto ao título, algo que o tradutor afirma "[estar] certo de que Ben Jonson aprovaria" (JOSÉ, 1987, p. 6). Assim como a primeira escolha em relação à adaptação e as suas justificativas em relação a isso, a vontade de mudar o título dessa forma parece indicar uma inclinação à domesticação (VENUTI, 1995) em seu projeto, “trazendo o autor para casa" (VENUTI, 1995, p. 20).

\section{A escassa presença de Ben Jonson no Brasil: hipóteses}

Levando em consideração aquilo que debatemos até aqui, discutiremos agora algumas hipóteses para a escassa presença de traduções de Ben Jonson em território brasileiro, visto a sua posição dentro do contexto elisabetano e jacobino - como um dos dramaturgos mais representativos, ao lado de William Shakespeare - e hoje em dia em universidades ao redor do mundo. Essas hipóteses não têm a pretensão de serem definitivas ou exaurirem o assunto, mas sim oferecer reflexões e possibilidades para se pensar nessa ausência em larga escala de obras do dramaturgo em território brasileiro. 
A primeira das proposições seria em relação à produção predominante de comédias na carreira do dramaturgo. Ao longo dos séculos, percebe-se que menos atenção foi dispensada às comédias, tanto por acadêmicos quanto pelo próprio público e leitores, de forma geral. Isso se mostra mais claramente ao considerarmos o tratamento dado às comédias do contemporâneo ilustre de Jonson, William Shakespeare, que escreveu mais comédias que qualquer outro gênero teatral durante a sua carreira ${ }^{19}$. Como apontado pela professora Marlene Soares dos Santos:

[Há um] domínio da tragédia por [ela] ter sido brindada com uma discussão pelo famoso filósofo [Aristóteles] naquele que é considerado o primeiro livro de crítica literária [Poética]. Devido ao prestígio das tragédias em geral e as de Shakespeare, em particular, somente da metade do século passado em diante é que as suas [Shakespeare] peças começaram a merecer a atenção da crítica. (2006, p. 20).

Quando consideramos as traduções brasileiras de peças shakespearianas e não-shakespearianas das eras elisabetana e jacobina, percebe-se também uma prevalência de tragédias, como levantado em relação à tradução de peças shakespearianas por meio do banco de dados Escolha seu Shakespeare ${ }^{20}$. Como exemplos de traduções de obras não-shakespearianas temos os títulos presentes na coletânea traduzida por Bárbara Heliodora Dramaturgia Elizabetana (2015), que conta com Tamerlão e A Trágica História de Doutor Fausto, de Christopher Marlowe e A Tragédia Espanhola, de Thomas Kyd, além de outros projetos como o Eduardo II, em tradução de Elvio Funck e as traduções de Sir Thomas More e Arden de Faversham por Régis A. B. Closel, além de outros ${ }^{21}$. Sendo assim,

\footnotetext{
${ }^{19}$ Shakespeare escreveu quatorze comédias, além de onze tragédias e dez peças históricas (SOARES, 2016). ${ }^{20}$ Ao consultar o número de traduções de tragédias e comédias shakespearianas, percebe-se uma predominância de traduções das tragédias, com uma média de mais de oito traduções por peça, enquanto as comédias têm em média cinco traduções por peça. Para ter acesso ao banco de dados do Escolha seu Shakespeare, acesse http://www.dbd.puc-rio.br/shakespeare/index.htm.

${ }^{21}$ Thais M. Giammarco com Dido; Oliveira Cabral com Fausto; Luiz Bueno com Fausto e a adaptação de Luiz Aguiar Fausto e Dido, e outros ainda.
} 
havendo uma prevalência no estudo e tradução de tragédias em geral, tanto do drama shakespeariano quanto não-shakespeariano, vale a reflexão se esse destaque menor das comédias, sendo esse quase que unicamente o gênero produzido por Ben Jonson, pode ser uma das razões para uma menor disseminação de suas peças em língua portuguesa ${ }^{22}$.

A segunda hipótese aqui mencionada é em relação à percepção de Ben Jonson como um autor classicista. O termo classicismo pode ser pensado de duas formas: (i) "como um sistema literário e filosófico que afirma e celebra a existência de uma série de princípios atemporais e invariáveis de conduta e pensamento: atenção à forma, decoro, conhecimento, passado, imitação, consistência, fidelidade, valor pessoal”23 (MULRYAN, 2000, p. 163); e (ii) "um reconhecimento de que esses princípios estão incorporados nos escritos da antiga Grécia e Roma, que devem ser tomados como modelos por todos os escritores posteriores que desejam repetir o processo"24 (MULRYAN, 2000, p. 20). Jonson se encaixaria nas duas acepções do termo, de certa maneira. Assim como muitos outros escritores do século XVII, o dramaturgo buscava seguir modelos clássicos, inserindo-se em uma voga típica de um renascimento tardio nas artes e na literatura de matriz greco-latina. Somado a isso, Jonson era grande conhecedor de línguas clássicas e um autor que tentava aderir às unidades clássicas de lugar, tempo e ação propostas em Poética, de Aristóteles ${ }^{25}$. Esse aspecto de seu trabalho está relacionado com a própria biografia do dramaturgo, dado que ele estudou na Westminster School com William Camden, humanista e historiador importante à sua época, conforme já apontamos.

\footnotetext{
22 Tendo em vista que há também muitas poucas publicações de peças traduzidas de Jonson em Portugal (ZURBACH, 2007), como previamente mencionado.

23 "a literary and philosophical system that asserts and celebrates the existence of a series of timeless, unvarying principles of conduct and thought: attention to form, decorum, knowledge, the past, imitation, consistency, fidelity, personal worth"

24 "an acknowledgment that those principles are embodied in the writings of ancient Greece and Rome, which should be taken as models by all later writers aspiring to repeat the process."

${ }^{25}$ De forma bem simplificada, as unidades aristotélicas afirmam que uma tragédia (ou peça de forma geral) teria que ocorrer em um único espaço físico (lugar), em um período de menos de 24 horas; e também ter uma única ação principal (ação).
} 
Assim como defendido por John Mulryan (2000), “Jonson obviamente queria que seu trabalho fosse considerado 'clássico' no sentido de uma obra que resistisse à passagem do tempo"26 (p. 164). Muitas vezes, percebe-se na obra de Jonson, muito por meio de seus próprios paratextos, o quanto ele estimava esses ideais classicistas, e como isso muitas vezes era colocado acima da própria estima do público. Como afirmado por Mulryan, no entanto, “Jonson, ainda assim, usa os clássicos em vez de ser usado por eles"27 (MULRYAN, 2000, p. 164).

O classicismo de Jonson - que fez com que algumas de suas peças não fossem especialmente populares nos teatros - ia, de certa forma, contra o que outros dramaturgos contemporâneos estavam fazendo naquela mesma época, como Shakespeare, por exemplo. Como a crítica de Sir Philip Sidney (1554-1586) em A Defense of Poesy ou Apologie for Poesie (1595) já aponta, "nossas tragédias e comédias, contra as quais se protesta, justificadamente, não observam nem as regras, nem a propriedade, nem a arte poética"28 (SIDNEY, 2002, p. 131-132). Além disso, as marcas classicistas na obra jonsoniana podem ser encaradas também como mais um desafio ao tradutor de seus textos, pois poderiam significar a necessidade de diversas notas com explicações acerca de inspirações, referências e alusões à cultura clássica. Pergunta-se então se essa posição classicista do autor poderia ter de fato dificultado a difusão de sua obra, principalmente em diferentes sistemas receptores, visto que Shakespeare tinha uma relação menos celebratória e mais transgressora da herança clássica que lhe antecedia, e é hoje o autor mais famoso do Renascimento inglês.

A terceira e última hipótese se relaciona com a anterior, pois fala da comparação inevitável entre Ben Jonson e seu contemporâneo, William Shakespeare - os dramaturgos considerados por muitos os mais representativos do início da Era Moderna inglesa, embora ofereçam versões

\footnotetext{
26 "Jonson obviously wanted his own work to be regarded as 'classical' in the sense of an oeuvre that can stand the test of time."

27 "Jonson still uses the classics rather than being used by them."

${ }^{28}$ Embora Sidney tenha falecido antes de ver o verdadeiro apogeu do teatro inglês nas eras elisabetana e jacobina.
} 
distintas desse passado (BUTLER; RICKARD, 2020). Como apontado por Newton Belleza em seu paratexto de Volpone, Jonson foi "praticamente um sucessor de ninguém, no seu tempo" (BELLEZA, 1977b, p. 18). Ao ler suas obras, torna-se evidente o estilo diferenciado adotado em suas comédias em relação às peças de Shakespeare. Jonson, por exemplo, explora bastante o contexto londrino em muitas de suas obras, sobretudo nas chamadas "city comedies", gênero no qual Shakespeare não produziu, e que demandam do leitor/espectador a compreensão de uma gama vasta de topicalidades que podem ser desafiadoras ao tradutor. A comparação entre os dois dramaturgos de fato moldou grande parte da recepção de Jonson ao longo dos séculos. Como apontado por Jonas Barish, "nenhum outro autor foi tão punido pelo crime de não ser Shakespeare" 29 (BARISH, 1963, p. 1 apud BUTLER; RICKARD, 2020, p. 21). Tendo em vista que Shakespeare é o dramaturgo mais famoso nos dias de hoje do teatro e da literatura do início da Era Moderna inglesa, momento histórico no qual Jonson também produziu, pergunta-se então se a fama de um, ao invés de encorajar a leitura do outro, poderia ter de fato dificultado a circulação de suas obras, se pensarmos no contexto brasileiro.

\section{Considerações finais}

Buscou-se, com o que foi apresentado neste artigo, refletir não só sobre os paratextos das duas únicas traduções publicadas do teatro de Ben Jonson no Brasil, mas também, de forma mais geral, sobre a recepção do dramaturgo em nosso território nacional. Tal reflexão nos leva a perguntar se a falta de traduções de suas peças, à exceção de Volpone, é responsável, pelo menos em parte, pela tímida presença de sua obra em âmbitos acadêmicos e gerais; ou se o contrário é verdadeiro. O drama não-shakespeariano do Renascimento inglês ainda tem pouca projeção no Brasil, mas é inegável a contribuição que uma visão mais abrangente do período traria até mesmo para uma compreensão mais contextualizada das peças de Shakespeare. Os períodos elisabetano e jacobino

29 "no author has been so punished for the crime of not being Shakespeare". 
foram uma época em que o teatro era marcadamente colaborativo, com seus dramaturgos respondendo uns aos outros e influenciando-se mutuamente. Sendo assim, o estudo e a disponibilidade de outras obras dramáticas, além do cânone shakespeariano, se mostra vital para um entendimento mais adensado do Renascimento inglês e da dramaturgia complexa que a época escreveu e encenou. De fato, embora muitas das peças de Jonson possam ser compreendidas como críticas à vida londrina de seu momento histórico, o seu humor ainda pode divertir e satirizar os dias de hoje, além de oferecer um contraponto interessante às comédias de Shakespeare e até mesmo àquelas produzidas na atualidade.

\section{Referências}

A COLEÇÃO TEATRO CLÁSSICO. In: JONSON, Ben. Volpone, ou A Raposa. Rio de Janeiro: Editora Emebê, 1977, p. 9.

BATCHELOR, Kathryn. Translation and paratexts. New York: Routledge, 2018. BELLEZA, Newton. Introdução. In: SHAKESPEARE, William. Amansando Catarina. Tradução de Newton Belleza. Rio de Janeiro: Editora Emebê, 1977a.

BELLEZA, Newton. O teatro de Ben Jonson. In: JONSON, Ben. Volpone ou a Raposa. Tradução de Newton Belleza. Rio de Janeiro: Editora Emebê, 1977b, p. 17-35.

BUTLER, Martin; HICKARD, Jane. Introduction. In: BUTLER, Martin; RICKARD, Jane (Ed.). Ben Jonson and Posterity: Reception, Reputation, Legacy. Cambridge: Cambridge University Press, 2020, p. 1-22.

GENETTE, Gérard. Paratexts: Thresholds of interpretation. Cambridge: Cambridge University Press, 1997.

GENETTE, Gérard. Introdução. In:____. Paratextos editoriais. Tradução de Álvaro Faleiros. São Paulo: Ateliê Editorial, 2009, p. 09-20. 
GENETTE, Gérard. Cinco tipos de transtextualidade, dentre os quais a hipertextualidade. In: . Palimpsestos: a literatura de segunda mão. Tradução de Luciene Guimarães. Belo Horizonte: Edições Viva Voz, 2010, p. 1321.

GOMES, Eugênio. A tradução de Volpone. In: JONSON, Ben. Volpone ou A Raposa. Tradução de Newton Belleza. Rio de Janeiro: Editora Emebê, 1977, p. 11-16.

JOSÉ, Ganymédes. Prefácio. In: JONSON, Ben. Volpone ou A Raposa. Adaptação de Ganymédes José. Rio de Janeiro: Editora Tecnoprint, 1987, p. 5-6.

LEECH, Clifford. Ben Jonson. Encyclopædia Britannica. Disponível em: < https://www.britannica.com/biography/Ben-Jonson-English-writer>. Último acesso em: 20 Jun 2020.

MARTINS, Marcia A.P. A voz dos tradutores shakespearianos em seus paratextos. Tradterm 26, 2015, p. 87-120.

MULRYAN, John. Jonson's classicism. In: The Cambridge Companion to Ben Jonson. Cambridge: Cambridge University Press, 2000, p. 163-74.

PARKER, Brian. Introduction. In: JONSON, Ben. Volpone; or, The Fox. Manchester: Manchester University Press, 1999, p. 1-60.

SANTOS, Marlene Soares dos. Shakespeare: as comédias. Belo Horizonte: Tessitura, CESh, 2016.

SCHEVE, D. A. Jonson's Volpone and Traditional Fox Lore. The Review of English Studies, v. 1, n. 3, p. 242-244, 1950.

SHAPIRO, James. The year of Lear: Shakespeare in 1606. New York: Simon and Schuster, 2016.

SIDNEY, Sir Philip; SHELLEY, Percy Bisshe. Defesas da poesia. Ensaio, tradução e notas de Enid Abreu Dobránsky. São Paulo: Iluminuras, 2002.

VENUTI, Lawrence. Invisibility. In: The Translator's Invisibility: a history of translation. London: Routledge, 1995. 
ZURBACH, Christine. A Tradução teatral: o texto e a cena. Porto: Caleidoscópio - Edições e Artes Gráficas, 2007.

WYLER, Lia. Línguas, poetas e bacharéis: uma crônica da tradução no Brasil. Rio de Janeiro: Rocco, 2003.

\title{
Resumo
}

Ben Jonson (1572-1637), dramaturgo e poeta inglês das eras elisabetana e jacobina e autor aclamado já a seu tempo, ainda conta com escassas traduções no Brasil, apesar de ter suas obras amplamente lidas, encenadas e traduzidas em diversas partes do mundo. Este artigo se propõe, então, a analisar os paratextos das únicas traduções publicadas para o português brasileiro de peças teatrais de Jonson a fim de pensar no porquê de o autor ter sido pouco traduzido ao longo da história editorial brasileira. Para isso, faremos uso do conceito de paratexto proposto por Gérard Genette (2009; 2010), além de discutir outras acepções do conceito e a razão pela qual decidimos utilizá-lo em nossa fundamentação teórica, levando em consideração também o contexto de produção dessas traduções. Os paratextos aqui analisados pertencem a traduções da peça Volpone, ou a Raposa (1605-06), sendo a primeira feita por Newton Belleza (1977) e a segunda por Ganymédes José (1987). Além disso, trabalharemos com uma resenha que comenta a tradução de Belleza, publicada na época em que ela foi produzida.

Palavras-chave: Estudos da Tradução; Era Jacobina; Ben Jonson; Volpone, ou A Raposa; Paratextos

\begin{abstract}
Ben Jonson (1572-1637), English playwright and poet from the Elizabethan and Jacobean eras and already an acclaimed author in his time, still has few translations of his work in Brazil, despite it being widely read, performed, and translated across the globe. This article aims at analysing the paratexts of the only published translations of plays by Ben Jonson (1572-1637) into Brazilian Portuguese to attempt to understand why there are not more translations of
\end{abstract}


works by this author in Brazil. To that end, this piece will use Gérard Genette's concept of paratexts $(1997 ; 2010)$, besides discussing other meanings of the term and the reason we decided to make use of this notion in our theoretical foundation. The two paratexts here analysed belong to translations of the play Volpone; or, The Fox (1605/1606), the first one produced by Newton Belleza in 1977 and the second one by Ganymédes José in 1987. Moreover, this article will also work with a review that comments on Belleza's translation, published at the time it was produced. In addition, hypotheses will be brought forward as to the reasons behind the absence of translations of works by Jonson in Brazil.

Keywords: Translation Studies; Jacobean Era; Ben Jonson; Volpone; or, The Fox; Paratexts 


\section{Anexo I}

Figura 1 - Pantalone da commedia dell'arte italiana

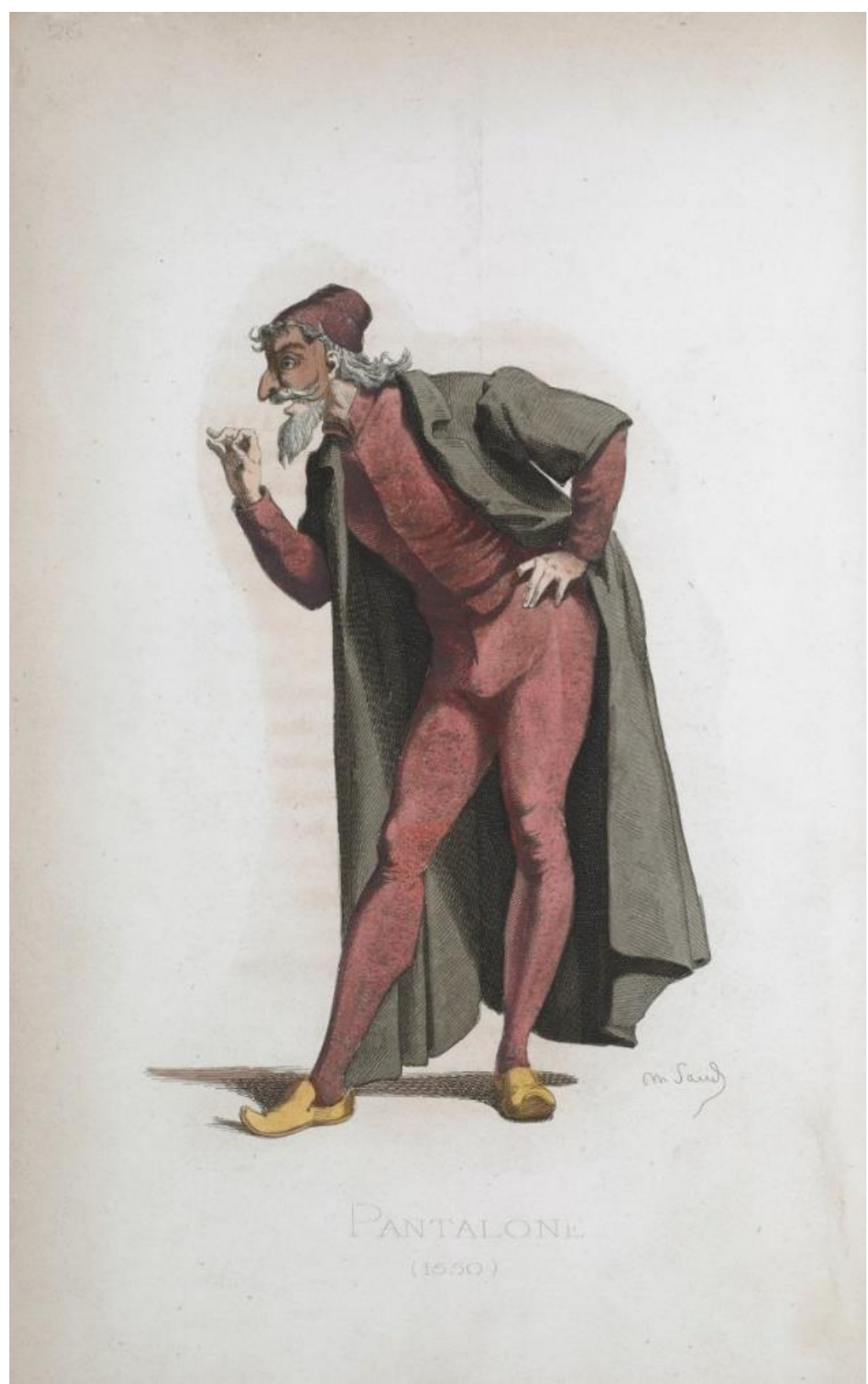

Fonte: https://www.bl.uk/collection-items/commedia-dell-arte-figures-bymaurice-sand- 1860 
Figura 2 - Resenha de Eugênio Gomes

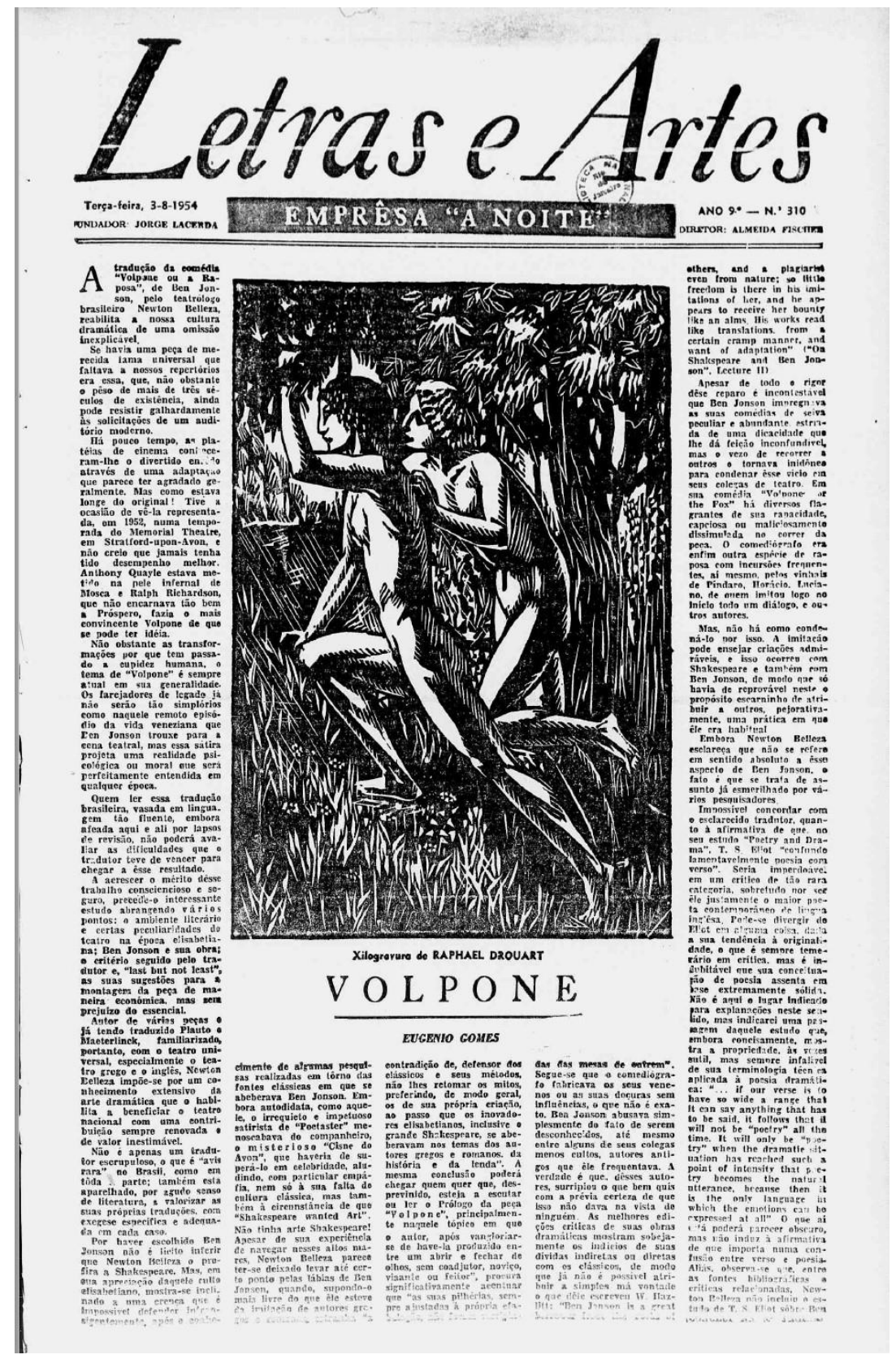

Fonte: $\underline{\text { http://memoria.bn.br/pdf/114774/per114774 } 1954 \text { 00310.pdf }}$ 
Figura 3 - Capa da edição de 1977

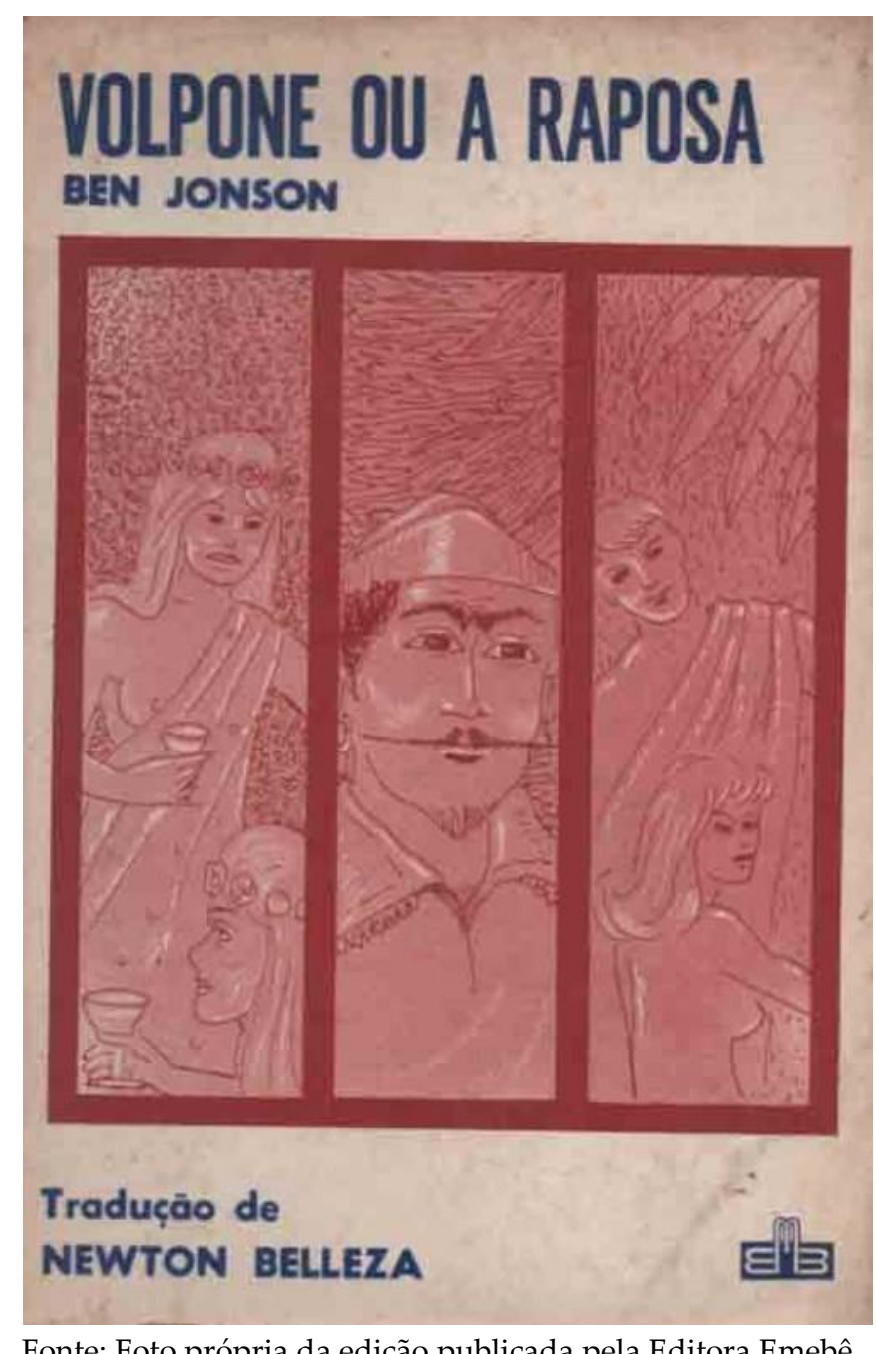

Fonte: Foto própria da edição publicada pela Editora Emebê. 
Figura 4 - edição de 1987

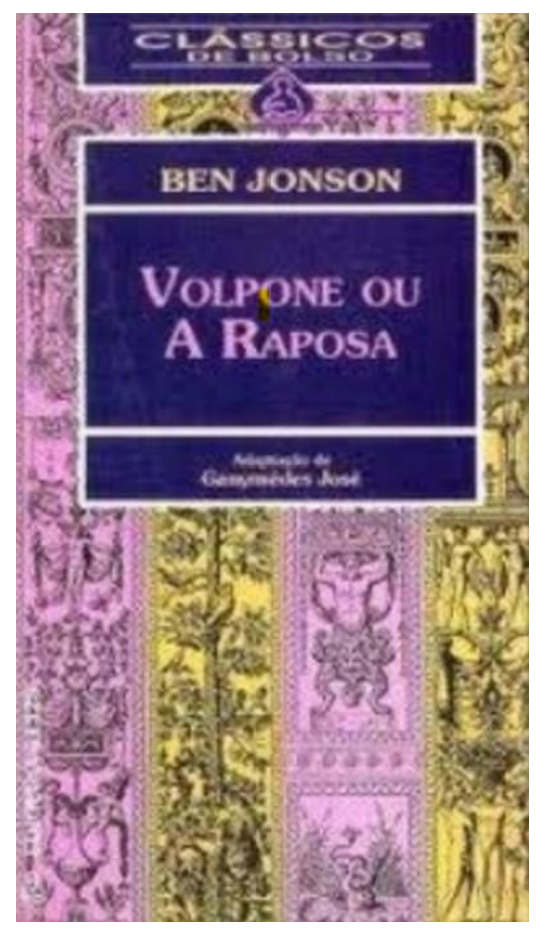

Fonte: Foto própria da edição publicada pela Editora Tecnoprint. 